in vivo $32: 1309-1321(2018)$

doi:10.21873/invivo.11381

\title{
Cytotoxicity and Pro-/Anti-inflammatory Properties of Cinnamates, Acrylates and Methacrylates Against RAW264.7 Cells
}

\author{
YUKIO MURAKAMI, AKIFUMI KAWATA, SEIJI SUZUKI and SEIICHIRO FUJISAWA
}

\author{
Division of Oral Diagnosis and General Dentistry, Department of Diagnostic and Therapeutic Sciences, \\ Meikai University School of Dentistry, Sakado, Japan
}

\begin{abstract}
Background/Aim: Periodontitis is a chronic inflammatory disease linked to various systemic age-related conditions. It is known that $\alpha, \beta$-unsaturated carbonyl compounds such as dietary cinnamates ( $\beta$-phenyl acrylates) and related (meth)acrylates can have various positive and negative health effects, including cytotoxicity, allergic activity, pro-and anti-inflammatory activity, and anticancer activity. To clarify the anti-inflammatory properties of $\alpha, \beta$-unsaturated carbonyl compounds without a phenolic group in the context of periodontal tissue inflammation and alveolar bone loss, we investigated the cytotoxicity and up-regulatory/downregulatory effect of three trans-cinnamates (trans-cinnamic acid, methyl cinnamate, trans-cinnamaldehyde), two acrylates (ethyl acrylate, 2-hydroxyethyl acrylate), and three methacrylates (methyl methacrylate, 2-hydroxyethyl methacrylate, and triethyleneglycol dimethacrylate) using RAW264.7 cells. Materials and Methods: Cytotoxicity was determined using a cell counting kit (CCK-8) and mRNA expression was determined using real-time reverse transcriptase-polymerase chain reaction (RT-PCR). Proinflammatory and anti-inflammatory properties were assessed in terms of expression of mRNAs for cyclo-oxygenase-2 (Cox2), nitric oxide synthase 2 (Nos2), tumor necrosis factoralpha (Tnfa) and heme oxygenase 1 (Hol). Results: The most cytotoxic compound was 2-hydroxyethyl acrylate, followed by ethyl acrylate and cinnamaldehyde $50 \%$ lethal cytotoxic
\end{abstract}

This article is freely accessible online.

Correspondence to: Dr. Yukio Murakami, Division of Oral Diagnosis and General Dentistry, Department of Diagnostic and Therapeutic Sciences, Meikai University School of Dentistry, 1-1 Keyakidai, Sakado City, Saitama 350-0283, Japan. Tel: +81 492855511, Fax: +81 492876657, e-mail: ymura@dent.meikai.ac.jp

Key Words: Cinnamates, (meth)acrylates, cytotoxicity, pro-/antiinflammatory properties, RAW264.7 cells, Cox2, Nos2 and Hol mRNA, ${ }^{13} \mathrm{C}$-NMR spectra, $\beta$-carbon. concentration, $L C_{50}=0.2-0.5 \mathrm{mM}$ ). Cox $2 \mathrm{mRNA}$ expression was up-regulated by cinnamaldehyde and 2-hydroxyethyl acrylate, particularly by the former. In contrast, the upregulatory effect on Nos 2 mRNA expression was in the order: cinnamaldehyde $>>$ ethyl acrylate $\approx$ triethyleneglycol dimethacrylate $>>$ methyl methacrylate $\approx$ methyl cinnamate. On the other hand, cinnamic acid and 2-hydroxyethyl methacrylate had no effect on gene expression. The two acrylates, but not cinnamates and methacrylates, up-regulated the expression of Hol mRNA at a non-cytotoxic concentration of $0.1 \mathrm{mM}$. Expression of Cox 2 , Nos 2 and Tnfa mRNAs induced by Porphyromonas gingivalis lipopolysaccharide was greatly suppressed by cinnamaldehyde, methyl cinnamate and the two acrylates at $0.1 \mathrm{mM}(p<0.05)$, and slightly, but significantly suppressed by cinnamic acid and methacrylates at 0.1-1 mM $(p<0.05)$. Conclusion: Cinnamaldehyde and acrylates exhibited both anti-inflammatory and proinflammatory properties, possibly due to their marked ability to act as Michael reaction acceptors, as estimated from the beta-carbon ${ }^{13} \mathrm{C}$-nuclear magnetic resonance spectra. Methyl cinnamate exhibited potent anti-inflammatory activity with less cytotoxicity and pro-inflammatory activity, suggesting that this compound may be useful for treatment of periodontal disease and related systemic diseases.

Cinnamates, acrylates and methacrylates, and $\alpha, \beta$-unsaturated carbonyl compounds act as Michael reaction acceptors (Figure 1). Dietary cinnamates with a phenylpropanoid structure $\left(\mathrm{C}_{6}-\mathrm{C}_{3}\right)$ such as cinnamaldehyde, methyl cinnamate and cinnamic acid, are $\beta$-phenyl acrylates. These compounds are known to have interesting multifunctional properties including cytotoxicity, anti-ultraviolet (UV) activity, antioxidant activity, pro-and anti-inflammatory activity, and anti-ulcerogenic, antipyretic, antimicrobial, antidiabetic and antitumor activity (1-7). Acrylates and methacrylates are also widely used clinically as polymer materials in the medical and dental fields. Especially in the context of dentistry, these compounds can produce low amounts of monomer residues 
<smiles>C=CC(=O)OCCO</smiles>

2-HEA<smiles>C=C(C)C(=O)OCCO</smiles>

2-HEMA<smiles>O=C/C=C/c1ccccc1</smiles>

CMA<smiles>C=C(C)C(=O)OCCOCCOCCOC(=O)C(=C)C</smiles>

TEGDMA<smiles>C=C(C)C(=O)OC</smiles>

MMA<smiles>COC(=O)/C=C/c1ccccc1</smiles>

MC<smiles>C=CC(=O)OCC</smiles>

EA<smiles>O=C(O)/C=C/c1ccccc1</smiles>

CA

Figure 1. The chemical structures of 2-hydroxyethyl acrylate (2-HEA), triethyleneglycol dimethacrylate (TEGDMA), 2-hydroxyethyl methacrylate (2-HEMA), methyl methacrylate (MMA), ethyl acrylate (EA), trans-cinnamaldehyde (CMA), methyl cinnamate (MC) and trans-cinnamic acid (CA). $\alpha$, Alpha carbon; $\beta$, beta carbon.

when used in dentures, restorative resins and adhesives, thereby possibly having adverse effects such as cytotoxicity, skin sensitization, mutagenicity, carcinogenicity, respiratory allergy, and organ toxicity (8-11). The adverse effects of cinnamates and (meth)acrylates may be due to their ability to induce oxidative stress and their covalent interactions with cellular nucleophiles such as proteins, histidine, lysine, glutathione $(\mathrm{GSH})$ and DNA bases $(7,8,11,12)$. The Michael addition of electrophilic cinnamates and (meth)acrylates to endogenous cysteine thiol plays a role in pathologies associated with oxidative stress (13), in the antiinflammatory activity of cyclopentane prostaglandins (14), and in the induction of enzymes that protect against carcinogenesis (15-17).

Cinnamates, acrylates and methacrylates, which are thiolreactive electrophiles, induce enzymes that are involved in their metabolism, particularly phase II detoxication enzymes such as glutathione-S-transferase, uridine diphosphate glucuronosyl transferase and nicotinamide adenine dinucleotide phosphate $[\mathrm{NAD}(\mathrm{P}) \mathrm{H}$ :quinone oxide reductase (NQOR1)] $(15,18-21)$. The NQOR1-inductive effects of $\alpha, \beta$-unsaturated carbonyl compounds may be related to their anti-inflammatory activity in most cells and tissues.
In general, inflammatory activity is accompanied by overexpression of nitric oxide synthase 2 (NOS2), leading to production of nitric oxide, which enhances the catalytic activity of cyclooxygenase-2 (COX2) via formation of the peroxinitrite anion (22). COX2 is a downstream target of NOS2. In addition, heme oxygenase-1 (HO1), the inducible isoform of $\mathrm{HO}$, catalyzes the degradation of heme into biliverdin, iron, and carbon monoxide, and inhibits immune responses and inflammation in vivo. Biliverdin and bilirubin are potent antioxidants that attenuate oxidative stress (23), and HO1 has anti-inflammatory, antioxidant, and antiproliferative effects $(22,24,25)$.

Chronic periodontal inflammation is a risk factor for systemic problems such as cardiovascular disease, diabetes mellitus and osteoporosis because of the transport of contributory factors via the blood circulation (26). The rodshaped, gram-negative anaerobic bacterium Porphyromonas gingivalis is considered to be the major causative agent of periodontitis. P. gingivalis lipopolysaccharide (LPS), a component of the cell wall, acts as a powerful activator of macrophages through the production of pro-inflammatory cytokines (27). Therefore, inhibition of COX2, NOS2 and tumor necrosis factor-alpha (TNFa) protein or gene expression 
in $P$. gingivalis LPS-stimulated gingival fibroblasts and RAW264.7 cells may be one way to screen anti-inflammatory antioxidant agents for their effects on age-related chronic diseases such as periodontitis with systemic problems. In this context, HO1 expression may be useful as a target for antiinflammatory antioxidant drugs and preventive agents against such age-related chronic diseases such as periodontitis (2831). We previously reported that the inhibitory effects of phenylpropanoids, including eugenol, bis-eugenol (the orthodimer of eugenol), magnolol, honokiol and curcumin on Escherichia coli LPS-induced RAW264.7 cells in terms of the release of pro-inflammatory mediators and cytokines, suggested that these compounds had potent anti-inflammatory activities $(30,31)$.

In the present study, firstly we investigated the cytotoxicity of $\alpha, \beta$-unsaturated carbonyl compounds, namely three cinnamates (cinnamaldehyde, methyl cinnamate, and cinnamic acid), two acrylates (2-hydroxyethyl acrylate, ethyl acrylate) and three methacrylates (methyl methacrylate, 2-hydroxyethyl methacrylate, triethyleneglycol dimethacrylate) towards RAW264.7 cells using a Cell Counting Kit-8 (CCK-8). RAW 264.7 cells were used to elucidate implications of these compounds in periodontal tissue inflammation and alveolar bone loss. Secondly, we then investigated the stimulatory effects of these compounds on expression of Nos2, Cox2 and Hol mRNA expression in this cell line. Subsequently, we investigated whether they these compounds inhibited the expression of mRNAs for Nos2, Cox 2 and Tnfa in $P$. gingivalis LPS-stimulated RAW264.7 cells. On the basis of our results, we considered whether the cytotoxicity of cinnamates and (meth)acrylates is dependent on the pi-electron density of the $\alpha, \beta$-carbon in these compounds. The higher the pi-electron density of the $\beta$-carbon, the higher the magnetic field at which the nuclear magnetic resonance (NMR) peak is observed, leading to a reduction of the NMR chemical shift. On this premise, we examined the relationship between the cytotoxicity, pro-inflammatory properties or anti-inflammatory properties and the NMR chemical shift of the $\beta$-carbons, and the site of electrophilic activity of cinnamates and (meth)acrylates.

\section{Materials and Methods}

Materials. Acrylates (ethyl acrylate, 2-hydroxyethyl acrylate), methacrylates [methyl methacrylate, 2-hydroxyethyl methacrylate, triethyleneglycol demethacrylate (TEGDMA)] and $\mathrm{N}$-acetyl-L-cysteine (NAC) were purchased from Tokyo Kasei Co. (Tokyo, Japan). Cinnamates (trans-cinnamic acid, methyl cinnamate, transcinnamaldehyde) were also purchased from Tokyo Kasei Co. The chemical structures of these compounds are shown in Figure 1. Solutions of these compounds were prepared by dissolving each of them in dimethyl sulfoxide, followed by dilution to the required concentrations using serum-free RPMI-1640 (Invitrogen Co., Carlsbad, CA, USA) as test samples. Fetal bovine serum (FBS) was obtained from HyClone (Logan, UT, USA). P. gingivalis ATCC33277 LPS was obtained from Wako Pure Chemical Industries (Osaka, Japan).

Cell culture. The murine macrophage-like cell line RAW264.7, obtained from Dainippon Sumitomo Pharma Biomedical Co. Ltd. (Osaka, Japan), was used. The cells were cultured to a subconfluent state in RPMI-1640 medium supplemented with $10 \%$ FBS at $37^{\circ} \mathrm{C}$ and $5 \% \mathrm{CO}_{2}$ in air, washed, and then incubated overnight in serumfree RPMI-1640. They were then washed again and treated with the test samples for cytotoxicity and real-time polymerase chain reaction.

Cytotoxicity. In brief, RAW264.7 cells $\left(3 \times 10^{4}\right.$ per well) were cultured in NUNC 96-well plates (flat-well-type microculture plates) $(100 \mu \mathrm{l})$ or $48 \mathrm{~h}$, after which the cells were incubated with acrylates, methacrylates or cinnamates at a concentration of 0.001 $100 \mathrm{mM}$ for $24 \mathrm{~h}$. The relative number of viable cells was then determined using a Cell Counting Kit-8 (CCK-8) (Dojindo Co., Kumamoto, Japan) (32). Ten microliters of CCK-8 solution was added to each well of the plate, which was then was incubated for 1 hour and then the absorbance was measured at $450 \mathrm{~nm}$ with a microplate reader (Biochromatic, Helsinki, Finland). $\mathrm{LC}_{50}$ values were determined from the dose-response curves. Data are expressed as means of three independent experiments. Statistical analyses were performed using Student's $t$-test and one-way ANOVA.

Effects of antioxidant NAC on ethyl acrylate or cinnamaldehyde effects. The cells were cultured for 48 hours, and then incubated with $1 \mathrm{mM}$ ethyl acrylate or cinnamaldehyde, with or without NAC at 1:1 molar ratio for $24 \mathrm{~h}$. CCK-8 solution was added to each well and then the absorbance was measured at $450 \mathrm{~nm}$ with a microplate reader in a similar manner as described above.

Preparation of total RNA and real-time polymerase chain reaction $(P C R)$. The preparation of total RNA and the procedure for realtime PCR have been described previously (33). In brief, RAW264.7 cells in NUNC 96-flat-well-type microculture plates $\left(10^{5}\right.$ cells per well) were pretreated for $30 \mathrm{~min}$ with or without acrylates, methacrylates and cinnamates at a concentration of $10-10,000 \mu \mathrm{M}$, and then incubated for $3.5 \mathrm{~h}$ with or without $P$. gingivalis LPS at $100 \mathrm{ng} / \mathrm{ml}$. Total RNA was then isolated using an RNeasy Plus Micro Kit (Qiagen Japan Co. Ltd., Tokyo, Japan) in accordance with the instruction manual. cDNA was synthesized from $2 \mu \mathrm{g}$ total RNA of each sample by random priming using a High Capacity RNA-tocDNA Kit (Life Technologies Japan, Tokyo, Japan). Reaction mixtures without the reverse transcriptase were used as a negative control. An aliquot of each cDNA synthesis reaction mixture was diluted and used for real-time PCR quantification. An equal-volume aliquot of each cDNA was mixed, serially diluted, and used as a standard. TaqMan probes/primers for Cox 2, Nos $2, \mathrm{Hol}$ and $18 \mathrm{~s}$ rRNA and the PCR enzyme mix for real-time PCR were purchased from Life Technologies Japan. Real-time PCR quantification was performed in triplicate using the GeneAmp Sequence Detection System 5700 software (Life Technologies Japan) in accordance with the instruction manual. The relative amount of target was calculated from standard curves generated in each PCR, and quantitative data with a coefficient of variance of less than $10 \%$ were used for further analyses. Each calculated amount of mRNA was standardized by reference to that for $18 \mathrm{~s}$ rRNA. Data are expressed as means of three independent experiments. Statistical analyses were performed using Student's $t$-test and one-way ANOVA. 
Table I. 50\% Lethal cytotoxic concentration $\left(L C_{50}\right)$ and hydrophobicity ( $\log P)$ for acrylates, methacrylates and cinnamates used in this study.

\begin{tabular}{lcc}
\hline Compound & $\mathrm{LC}_{50}(\mathrm{mM})$ & $\log \mathrm{P}^{\mathrm{a}}$ \\
\hline Experiment 1 & $1.19( \pm 0.04)$ & \\
Methyl methacrylate & $>0.9$ & 1.38 \\
2-Hydroxyethyl methacrylate & $0.89( \pm 0.04)$ & 1.55 \\
Triethyleneglycol dimethacrylate & $0.48( \pm 0.05)$ & 1.33 \\
Ethyl acrylate & $0.15( \pm 0.04)$ & $0.17^{\mathrm{b}}$ \\
2-Hydroxyethyl acrylate & & \\
Experiment 2 & $2.87( \pm 0.02)$ & $2.13^{\mathrm{c}}$ \\
$t$-Cinnamic acid & $12.07( \pm 0.01)$ & $2.62^{\mathrm{c}}$ \\
Methyl cinnamate & $0.44( \pm 0.02)$ & $1.91^{\mathrm{c}}$ \\
$t$-Cinnamaldehyde &
\end{tabular}

aTaken from Fujisawa and Kadoma (38); bTaken from Chan and O'Brien (10); 'hhtps://pubchem.ncbi.nim.nih.gov/t-cinnamaldehyde, methyl cinnamate, $\mathrm{t}$-cinnamic acid

\section{Results and Discussion}

Cytotoxicity and ${ }^{13} \mathrm{C}$-NMR chemical shifts. $\mathrm{LC}_{50}$ values and ${ }^{13} \mathrm{C}$-NMR chemical shifts of the $\alpha, \beta$-carbon $\left(\delta C_{\alpha}, \delta C_{\beta}\right)$ for (meth)acrylates and cinnamates are shown in Tables I and II, respectively. The rank order of cytotoxicity potency for (meth)acrylates was 2-hydroxyethyl acrylate $>$ ethyl acrylate $>$ TEGDMA > 2-hydroxyethyl methacrylates > methyl methacrylate; that for cinnamates was cinnamaldehyde $>$ cinnamic acid $>$ methyl cinnamate.

The cytotoxicity of 2-hydroxyethyl acrylate and ethyl acrylate was markedly greater than that of methacrylates. The $\mathrm{LC}_{50}$ value for 2-hydroxyethyl acrylate against RAW264.7 cells was similar to that against hepatocytes (10). Ethyl acrylate and methyl methacrylate had similar hydrophobicity $(\log \mathrm{P})$ but the cytotoxicity of the former was greater than that of the latter. As shown in Table II, the $\delta C_{\beta}$ value for ethyl acrylate was greater than that for methyl methacrylate, indicating that the electrophilicity of the former is greater than that of the latter. 2-Hydroxyethyl methacrylate was found to be far less cytotoxic than 2-hydroxyethyl acrylate, possibly due to the high electrophilic reactivity of the latter, resulting from the great difference of the $\delta C_{\beta}$ value between these compounds. Next, we investigated the relationship between the $\mathrm{LC}_{50}$ and the $\delta C_{\beta}$ value for (meth)acrylates. A good linear relationship between the two parameters was observed, as shown below:

$\mathrm{LC}_{50}=18.43( \pm 0.16)-0.14( \pm 0.03) \delta \mathrm{C}_{\beta}$

$\left(\mathrm{n}=4, \mathrm{r}^{2}=0.92, p<0.05\right)$

(Eq. 1)

2-Hydroxyethyl methacrylate was omitted from Eq. 1 because its cytotoxicity altered the reaction time.
Table II. ${ }^{13} \mathrm{C}$-Nuclear magnetic spectroscopy $(N M R)$ chemical shifts $(\delta)$ of $\beta$-carbon $\left(C_{\beta}\right), \alpha$-carbon $\left(C_{\alpha}\right)$ and electrophilicity $(\omega)$ for acrylates, methacrylates and cinnamates used in this study.

\begin{tabular}{lcccc}
\hline Compound & $\begin{array}{c}\delta \mathrm{C}_{\beta} \\
(\mathrm{ppm})\end{array}$ & $\begin{array}{c}\delta \mathrm{C}_{\alpha} \\
(\mathrm{ppm})\end{array}$ & $\begin{array}{c}\omega^{\mathrm{c}} \\
(\mathrm{eV})\end{array}$ & $\begin{array}{c}\omega^{\mathrm{d}} \\
(\mathrm{eV})\end{array}$ \\
\hline Methyl methacrylate & 125.23 & 136.15 & - & 2.681 \\
2-Hydroxyethyl methacrylate & 125.89 & 135.96 & - & 2.725 \\
Triethyleneglycol dimethacrylate & 125.50 & 136.50 & - & 2.452 \\
Methyl acrylate & 130.56 & 128.15 & - & 2.829 \\
Ethyl acrylate & 130.24 & 128.59 & 1.494 & 2.789 \\
2-Hydroxyethyl acrylate & $131.30^{\mathrm{a}}$ & $127.50^{\mathrm{a}}$ & 1.533 & 3.065 \\
$t$-Cinnamic acid & $141.55^{\mathrm{b}}$ & $126.83^{\mathrm{b}}$ & - & - \\
Methyl cinnamate & $144.79^{\mathrm{b}}$ & $117.92^{\mathrm{b}}$ & - & - \\
$t$-Cinnamaldehyde & $152.46^{\mathrm{b}}$ & $131.17^{\mathrm{b}}$ & 2.098 & - \\
\hline
\end{tabular}

${ }^{13} \mathrm{C}-\mathrm{NMR}$ chemical shifts of alpha and beta carbons for (meth)acrylates were taken from Ishihara and Fujisawa (50). The chemical shift was determined in $\mathrm{CDCl} 3$ and was converted to the tetramethylsilane scale. aAcrylic monomers, The Dow Chemical Company msds search dow com/Published literature DOW/COM/. bhttps://www.chemicalbook.com/ SpectrumEN_140-10-3, 103-26-4 and 14371-10-9_13C-NMR.htm. cTaken from Enoch et al. (53). ${ }^{\mathrm{d}}$ Taken from Ishihara and Fujisawa (52).

The cytotoxicity was closely positively correlated with the relative pi-electron density $\left(\delta \mathrm{C}_{\beta}\right)$ of the beta-carbon, i.e. the site of electrophilic activity. In addition, a linear relationship was observed between the $\mathrm{LC}_{50}$ and $\delta \mathrm{C}_{\alpha}$ values for these compounds $\left(r^{2}=0.87\right)$ (Table II), as $\delta C_{\alpha}$ decreased, the cytotoxicity increased.

In a similar context, it was shown previously that when acrylates and methacrylates are separated, the $\mathrm{LC}_{50}$ of an acrylate series against hepatocytes was linearly correlated with the partial charges of the carbon atoms that make up the $\alpha, \beta$-carbonyl structure; the partial charge of the carbon atoms was determined using semiempirical calculations. The hepatotoxicity of five acrylates in that study was linearly correlated with the increasing partial charge at the $\beta$-carbon $(p<0.05)$ and more significantly with the negative partial charge on the $\alpha$-carbon $(p<0.01)$ (10). However, the hepatotoxicity of acrylates was shown not to correlate with their lipophilicity $(\log$ P) (10). Organic chemistry has shown that nucleophilic addition to the electrophilic (electrondeficient) double bond generates a significant negative charge on the $\alpha$-carbon which is delocalized into the adjacent carbonyl moiety by pi-resonance (34). This suggests that the biological activity of acrylates without substituents at the $\alpha$ carbon may be more influenced by the $\alpha$-carbon than that by a $\beta$-carbon. Next, we investigated the relationship between the $\mathrm{LC}_{50}$ and $\delta \mathrm{C}_{\beta}$ or $\delta \mathrm{C}_{\alpha}$ values for cinnamates, and a good positive linear relationship was demonstrated between the $\mathrm{LC}_{50}$ and $\delta \mathrm{C}_{\alpha}\left(\mathrm{r}^{2}=0.91\right)$. The cytotoxicity of cinnamates may be attributed mainly to the pi-electron density at the alpha carbon. This was thought to be reasonable in view of the 
similar molecular structures of acrylates and cinnamates $(\beta$ phenyl acrylates) but the $\mathrm{LC}_{50}$ for acrylates was found to be negatively correlated with their $\delta C_{\alpha}$ value (10). The cytotoxicity of cinnamates and (meth)acrylates against RAW264.7 cells was also not affected by their hydrophobicity $(\log \mathrm{P})$.

In contrast, the cytotoxicity of methacrylates can be affected by a combination of electronic and steric factors introduced by methyl substitution on $\alpha$-carbons. We previously investigated the possible link between this cytotoxicity and $\mathrm{Ca}^{2+}$ mobilization in a human salivary gland carcinoma cell line and human gingival fibroblasts by (meth)acrylates. This revealed that hydrophilic 2-hydroxyethyl methacrylate, as well as acrylic acid and methacrylic acid, have low cytotoxicity and elicit only a small elevation of intracellular calcium concentration $\left[\mathrm{Ca}^{2+}\right]_{\mathrm{i}}$, whereas hydrophobic (meth)acrylates are cytotoxic and elicit a large $\left[\mathrm{Ca}^{2+}\right]_{\mathrm{i}}$ elevation (35). It is well established that variations in cytosolic calcium concentration, $\left[\mathrm{Ca}^{2+}\right]_{c}$, trigger key cellular functions, and that cellular $\mathrm{Ca}^{2+}$ overload is highly toxic, being related to the induction of apoptosis (36). The cytotoxicity of (meth)acrylates against human salivary gland carcinoma cell line and human gingival fibroblasts is related to their $\log \mathrm{P}$ (35), the cytotoxic mechanisms being dependent on the cell species and inducers involved. We also previously investigated the relationship between the in vivo toxicity of (meth)acrylates in mice (oral and intraperitoneal $50 \%$ lethal dose) and GSH reactivities predicted by their $\delta C_{\beta}$ values, demonstrating a good relationship between these parameters in series of both acrylates and methacrylates $(37,38)$. Despite a possible discrepancy between the in vivo and in vitro toxicities, the cytotoxicity of (meth)acrylates in RAW264.7 cells is affected by the electrophilicity of the monomers.

Next, to clarify the cytotoxic effects of GSH reactivity, the cytotoxicity of ethyl acrylate and cinnamaldehyde with or without the antioxidant NAC was investigated and the effect of NAC was evaluated. The results are shown in Figure 2. The cytotoxicity of both compounds was greatly reduced by addition of NAC. Cinnamaldehyde and ethyl acrylate probably interact spontaneously and more rapidly in the presence of NAC. This interaction may involve Michael-type addition between the nucleophilic NAC and electrophilic cinnamaldehyde or ethyl acrylate, and NAC may block the induction of monomer-mediated DNA and apoptosis. The mechanism of cinnamaldehyde cytotoxicity was investigated previously in isolated F344 rat hepatocytes, and the results suggested that cinnamaldehyde, but not cinnamic acid, reacted spontaneously with reduced GSH in vitro (39). Taken together with our results, the evidence suggests that the toxicity of cinnamaldehyde and ethyl acrylate is attenuated through interaction between the $\beta$-carbons of these compounds and NAC in vitro. However, at the cellular level, cinnamaldehyde and ethyl acrylate may induce a variety of

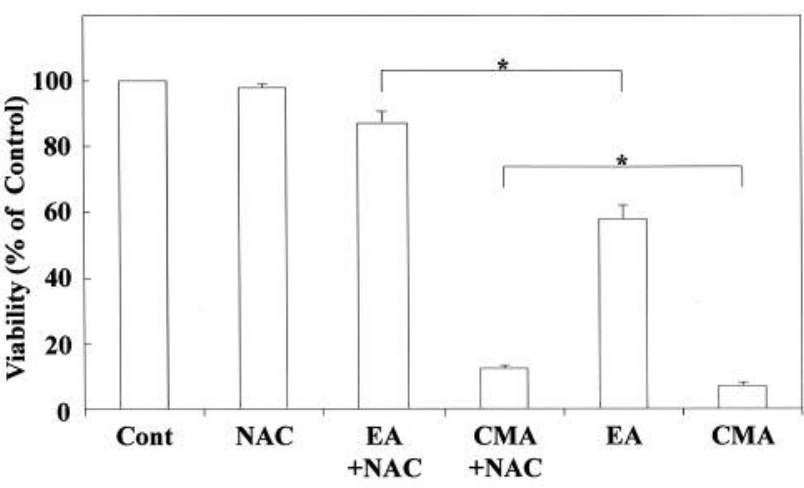

Figure 2. Inhibition of ethyl acrylate (EA)-and trans-cinnamaldehyde (CMA)-induced cytotoxicity by N-acetyl-L-cysteine (NAC) in RAW264.7 cells. The experimental procedure is described in the Materials and Methods. The results are presented as the means \pm standard error (SE) of three independent experiments, $S E<15 \%$. *Significantly different at $p<0.01$. Cont: Control without any additive.

stress responses in RAW264.7 cells, including GSH depression, oxidative stress, and mitochondrial dysfunction, as well as release of inflammatory mediators and proinflammatory cytokines, resulting in cell death.

Cox2 mRNA expression in RAW264.7 cells stimulated with cinnamates and (meth)acrylates. It has been well documented that the inflammatory response to $E$. coli and $P$. gingivalis LPS or $P$. gingivalis fimbriae involves the production of COX2, NOS2 and proinflammatory cytokines such as TNF $\alpha$, interleukin (IL)-6, and IL1 $\beta$ in RAW264.7 cells $(28,30,40)$. Contrary to the pro-inflammatory effects of LPS, the inflammatory mediators COX2 and NOS2 and cytokines such as TNF $\alpha$ at both the protein and gene levels may also be expressed in macrophages stimulated by $\alpha, \beta$ unsaturated carbonyl compounds.

Therefore, we investigated the expression of $\operatorname{Cox} 2$ mRNA in RAW264.7 cells stimulated by cinnamates, acrylates and methacrylates. The results are shown in Figures 3 and 4, respectively. Cinnamaldehyde stimulated Cox2 mRNA expression at $0.1 \mathrm{mM}$, whereas 2-hydroxyethyl acrylate stimulated its gene expression at $1 \mathrm{mM}$. Other compounds such as methyl cinnamates, ethyl acrylate and methacrylates had no effect on Cox 2 expression. The concentration of cinnamaldehyde required for induction of Cox 2 mRNA expression was approximately 10 -fold higher than that of 2-hydroxyacrylate. In this study, despite the relatively high $\delta C_{\beta}$ value for cinnamates, cinnamaldehyde was the most cytotoxic compound and potently elicited Cox 2 gene expression, possibly reflecting the fact that aldehydes tend to have higher inductive potency. Among (meth)acrylates, 2-hydroxyethyl acrylate was the most cytotoxic and had the 


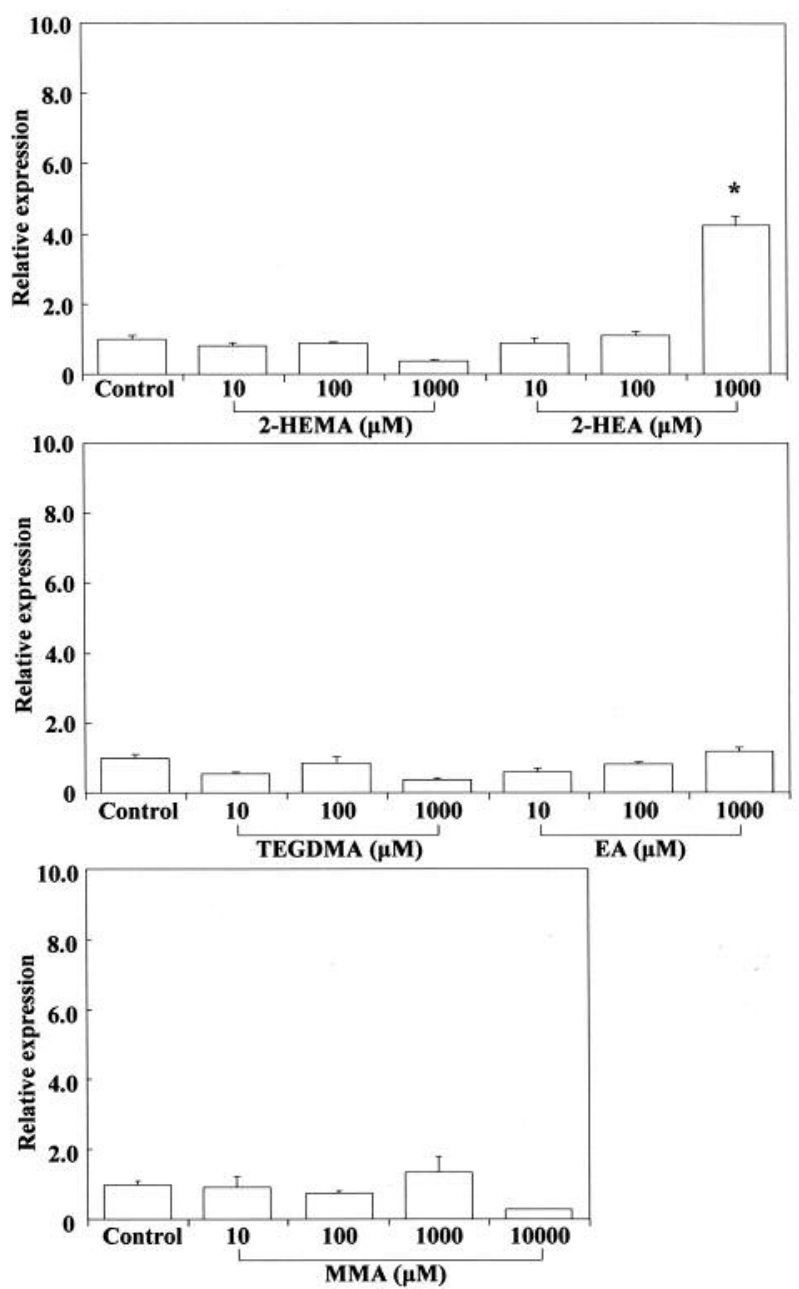

Figure 3. Stimulating effect of 2-hydroxyethyl methacrylate (2-HEMA), 2-hydroxyethyl acrylate (2-HEA), ethyl acrylate (EA), triethylenglycol dimethacrylate (TEGDMA) and methyl methacrylate (MMA) on cyclooxygenase-2 (Cox2) mRNA expression in RAW264.7 cells. The cells were incubated for $3.5 \mathrm{~h}$ with each compound at a concentration of 10-1,000 $\mu M$, and then their total RNAs were prepared. Each cDNA was synthesized, and the expression level of Cox 2 mRNA was determined by real-time polymerase chain reaction and standardized against the expression of $18 \mathrm{~s} r R N A$. The results are presented as means \pm standard error (SE) of three independent experiments, $S E<15 \%$. *Significantly different at $p<0.01$ vs. control group.

highest $\delta C_{\beta}$ value, possibly due to the induction of Cox2 gene expression. Macrophages and other activated inflammatory cells secrete high amounts of prostaglandin $E_{2}$ (PGE2), nitric oxide (NO), and cytokines such as IL6, $\mathrm{TNF} \alpha$, and IL1 $\beta$. COX2 is a key mediator of the inflammatory process, being responsible for production of PGE2 from arachidonic acid. Down-regulation of Cox2 is a condition for inhibition of PGE2, which is expressed in all processes that lead to major features of inflammation, i.e.

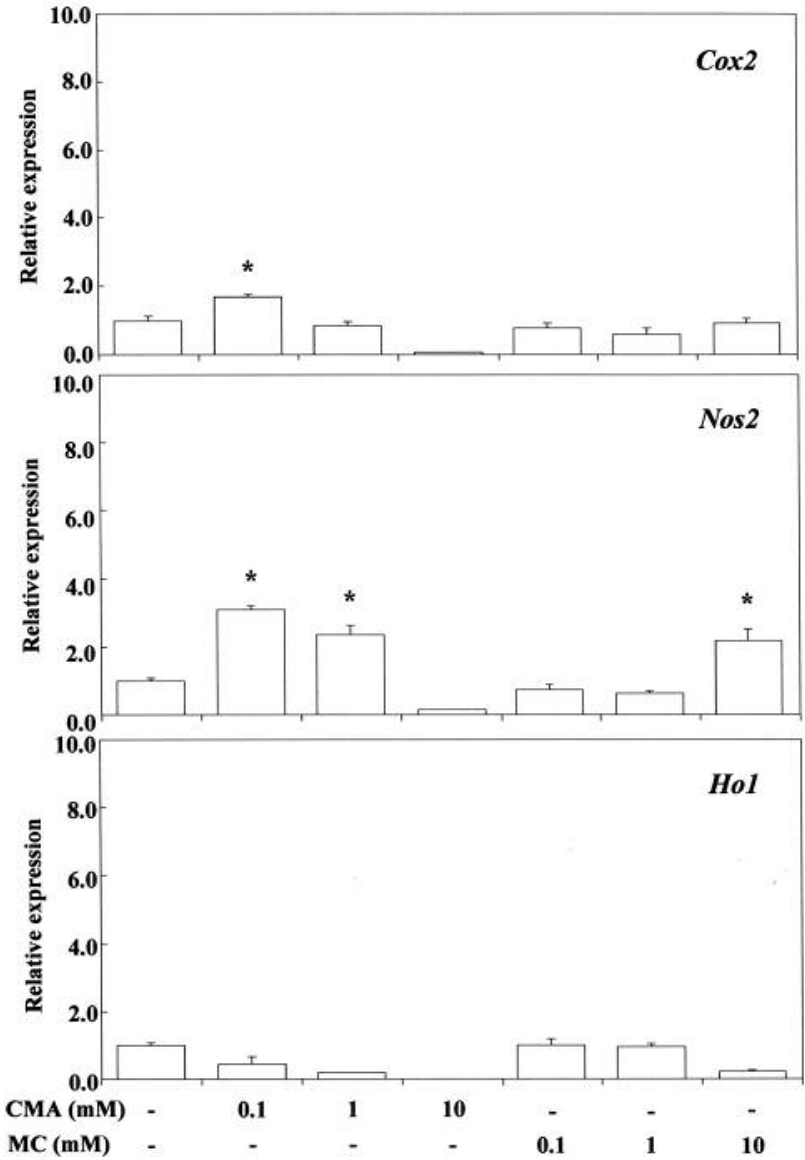

Figure 4. Stimulating effect of trans-cinnamaldehyde (CMA) and methyl cinnamate $(M C)$ on cyclo-oxygenase-2 (Cox2), nitric oxide synthase 2 (Nos2) and heme oxygenase 1 (Ho1) gene expression in RAW264.7 cells. The cells were incubated for $3.5 \mathrm{~h}$ with each compound at a concentration of 0.1-10 $\mathrm{mM}$, and then their total RNAs were prepared. Each cDNA was synthesized, and the expression level of each mRNA was determined by real-time polymerase chain reaction and standardized against the expression of $18 \mathrm{~s}$ rRNA. The results are presented as means \pm standard error (SE) of three independent experiments, $S E<15 \%$. *Significantly different at $p<0.01 \mathrm{vs}$. control group.

swelling, redness, and pain $(41,42)$. On the other hand, it is suggested that up-regulation of Cox 2 might lead to an increase of pro-inflammatory activity. It was shown that low concentrations (up to $1 \mu \mathrm{g} / \mathrm{ml}$ ) of cinnamaldehyde induce a slight increase in nuclear factor- $\mathrm{kB}(\mathrm{NF}-\mathrm{kB})$ activation (4), suggesting a degree of intrinsic pro-inflammatory activity. It has also occasionally been reported that cinnamaldehyde can induce intraoral allergic contact dermatitis; the most commonly implicated allergens are metals that are incorporated into dental appliances, but cinnamaldehyde is widely used as a flavoring agent in foods and dentifrices (43). Our results suggest that cinnamaldehyde ( $\beta$-phenyl 
acrolein) and 2-hydroxyethyl acrylate may exert cytotoxic/genotoxic cell damage in mammalian cells due to their high reactivity with cellular nucleophiles (e.g. Michael adduct formation with DNA bases and with GSH) (44-46).

In other contexts, cinnamaldehyde has been reported to exert marked antimutagenic effects against mutations induced by UV-mimic mutagens, but not those induced by $\mathrm{N}$-methyl$N$ '-nitro- $N$-nitrosoguanidine or ethyl methanesulfonate, suggesting that cinnamaldehyde may interfere with the inducible error-prone DNA-repair pathway (47). In contrast, 2-hydroxyethyl acrylate, ethyl acrylate and TEGDMA have been listed as mutagenic (45).

Stimulation of Nos 2 mRNA expression by cinnamates and (meth)acrylates. COX2 expression is selectively induced by pro-inflammatory cytokines at sites of inflammation, and NOS2 is also involved in the inflammatory process (48). NOS 2 may be expressed in macrophages after induction of oxidative stress due to cinnamates and (meth)acrylates. Cinnamaldehyde elicited Nos 2 mRNA expression at $0.1 \mathrm{mM}$, whereas methyl cinnamate did so at $10 \mathrm{mM}$, indicating that the inductive ability of the former is approximately two orders of magnitude greater than that of the latter. This may be due to the large electrophilicity of cinnamaldehyde, which has a reactive aldehyde moiety. 2-Hydroxyethyl acrylate, ethyl acrylate and TEGDMA elicited Nos 2 mRNA expression at the cytotoxic concentration of $1 \mathrm{mM}$ (Figure 5). Methyl methacrylate elicited Nos 2 mRNA expression at a high cytotoxic concentration of $10 \mathrm{mM}$, whereas 2-hydroxyethyl methacrylate and cinnamic acid were ineffective over a wide concentration range of 1-10 mM. These findings suggest that the up-regulatory effect of monomers on Nos 2 gene expression may not necessarily be controlled by their $\omega$ potency alone, and that the relative hydrophobic/hydrophilic balance of monomers is also important. Although methyl cinnamate and cinnamic acid have higher $\delta C_{\beta}$ values than 2hydroxyethyl or ethyl acrylate, they elicited weak Nos 2 gene expression and were not effective. Up-regulation of Nos 2 expression by TEGDMA, a dimethacrylate, may be attributable to the double Michael reaction acceptor. Production of PGE2 stimulated by TEGDMA, but not by 2hydroxyethyl methacrylate, has been reported previously in RAW264.7 cells (49). TEGDMA and 2-hydroxyethyl methacrylate do not affect the expression of inducible nitric oxide synthase (Inos) mRNA (49).

We previously investigated the cytotoxicity mechanism of (meth)acrylates (50), and eugenol-related compounds, using computational methods $(30,51)$. The energy values of the highest occupied molecular orbital (HOMO) and the lowest unoccupied molecular orbital (LUMO) energy are defined as $\mathrm{E}_{\text {LUMO }}$ and $\mathrm{E}_{\mathrm{HOMO}}$, respectively. Chemical hardness $(\eta)$, electronegativity $(\chi)$, electrophilicity $(\omega)$ and softness $(\sigma)$ are calculated using equations $2-5$, respectively:
$\eta=\left(\mathrm{E}_{\mathrm{LUMO}}-\mathrm{E}_{\mathrm{HOMO}}\right) / 2$

$\chi=-\left(\mathrm{E}_{\mathrm{LUMO}}+\mathrm{E}_{\mathrm{HOMO}}\right) / 2$

$\omega=\chi^{2} / 2 \eta$

$\sigma=1 / \eta$

(Eq. 2)

(Eq. 3)

(Eq. 4)

(Eq. 5)

The $\log \mathrm{LC}_{50}$ for phenyl propanoids, which are eugenolrelated compounds, was reported to be linearly and positively related to their $\omega$ value calculated using the B3LYP/6-31G* level ( $p<0.001)$ (30). In the present study, we also investigated the relationship between the $\omega$ and $\delta C_{\beta}$ values for cinnamaldehyde, 2-hydroxy acrylates and ethyl acrylate using cited data (Table II), and found that the $\omega$ value of these compounds was markedly linearly negatively correlated with their $\delta C_{\beta}$ value $\left(n=3, r^{2}=0.999\right.$, $p<0.01)$. We also calculated the $\omega$ value of (meth)acrylates using Eq.4 based on our previous data (52) (Table II), and examination of the relationship between the $\omega$ and $\delta C_{\beta}$ values for these compounds revealed a moderate positive linear correlation $(n=6$, $\left.r^{2}=0.662, p<0.05\right)$. These findings suggested that there is a linear relationship between the $\omega$ and $\delta C_{\beta}$ value for cinnamaldehyde and (meth)acrylates. It may therefore be possible to estimate the electrophilicity $(\omega)$ of $\alpha, \beta$ unsaturated carbonyl compounds from their $\delta C_{\beta}$ values. The $\omega$ value is a higher-order parameter that combines softness with electronegativity $(\chi)$ and represents a sensitive measure of electrophilic reactivity. The $\omega$ value has been used as a parameter of allergic dermatitis and allergic sensitization associated with $\alpha, \beta$-unsaturated carbonyl compounds (53), allergic potential increasing with the $\omega$ value. Induction of inflammatory mediators and cytokines by $\alpha, \beta$-unsaturated carbonyl compounds may be related to other parameters in addition to the $\omega$ value. The $\eta$ value (HOMO-LUMO energy gap) for (meth)acrylates was also calculated from our previous data using Eq. $2(38,50)$; the rank order magnitude of $\eta(\mathrm{eV})$ is ethyl acrylate (5.495) $>$ methyl acrylate $(5.492)>$ methyl methacrylate (5.245) $>$ 2-hydroxyethyl methacrylate (5.233) > 2-hydroxyethyl acrylate (5.174) $>$ TEGDMA (5.092). A lower $\eta$ value for bioactive compounds indicates that the molecules are more easily excitable. Therefore, their $\sigma$ values (softness) were calculated using Eq. 5.

The $\sigma$ value $(\mathrm{eV})$ for methyl methacrylates, 2-hydroxyethyl methacrylate, 2-hydroxyethyl acrylate and TEGDMA was $0.1907,0.1911,0.1932$ and 0.1936 , respectively, being grouped as having the most softness among the (meth)acrylates we tested. The $\sigma$ value indicates the ease with which electron redistribution takes place during covalent bonding, i.e. donation of electrons by nucleophiles and acceptance by electrophiles. Therefore, with respect to electrophilic species, it is often the case that softness (i.e. a higher $\sigma$ value) is correlated with the ease of adduct formation (54), that is, the $\sigma$ energy serves as a measure of 


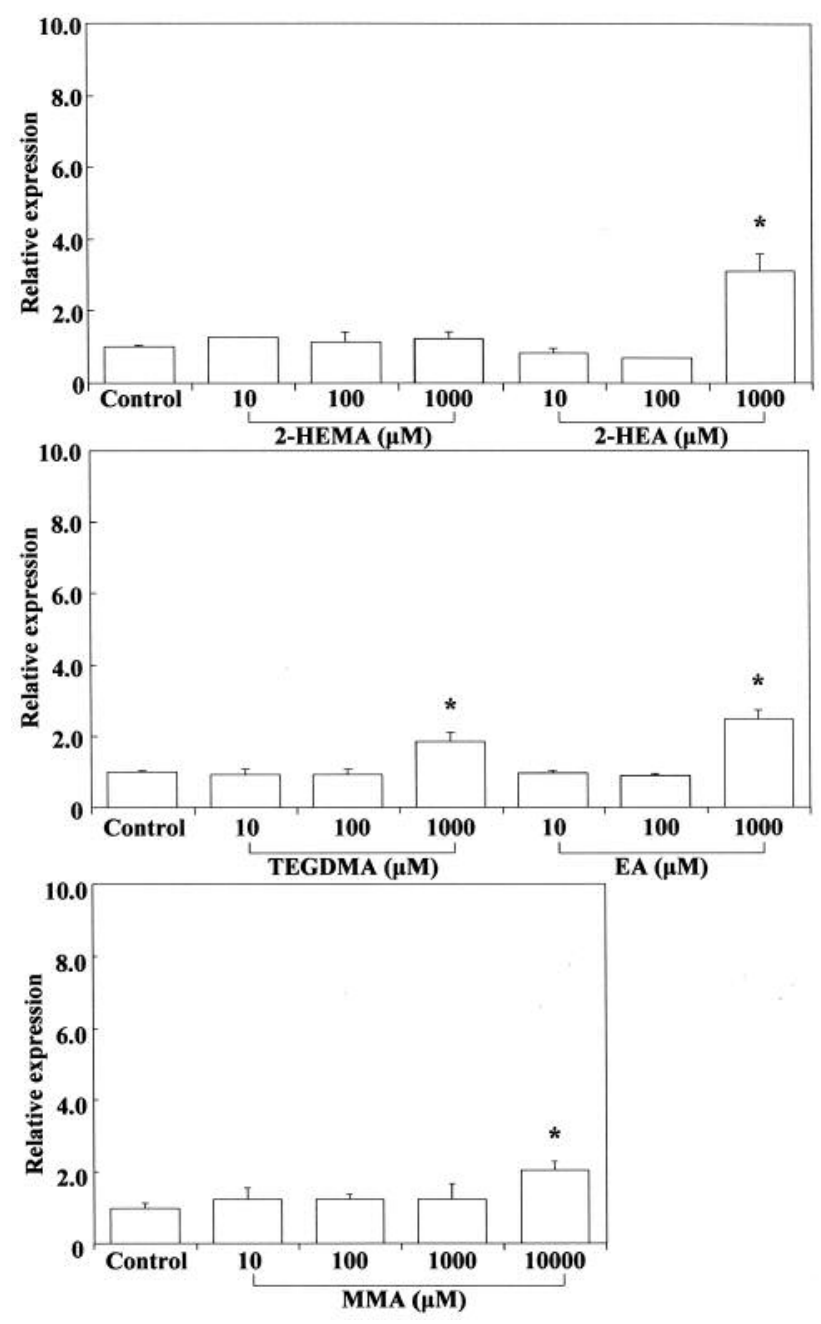

Figure 5. Stimulating effects of 2-hydroxyethyl methacrylate (2-HEMA), 2-hydroxyethyl acrylate (2-HEA), ethyl acrylate (EA), triethylenglycol dimethacrylate (TEGDMA) and methyl methacrylate (MMA) on nitric oxide synthase 2 (Nos2) mRNA expression in RAW264.7 cells. The cells were incubated for $3.5 \mathrm{~h}$ with each acrylate-related compound at a concentration of 10-1,000 $\mu \mathrm{M}$ then their total RNAs were prepared. Each cDNA was synthesized, and the expression level of each mRNA was determined by real-time polymerase chain reaction and standardized against the expression of $18 \mathrm{~s}$ rRNA. The results are presented as means \pm standard error (SE) of three independent experiments, $S E<15 \%$. *Significantly different at $p<0.01 \mathrm{vs}$. control group.

molecular excitability. Up-regulation of Nos 2 mRNA expression by TEGDMA and 2-hydroxyethyl acrylate may be related to their high softness (55). Although no stimulation of Nos 2 mRNA expression by 2-hydroxyethyl methacrylate was observed in the present study, it may be induced under certain conditions in view of its relatively high softness.
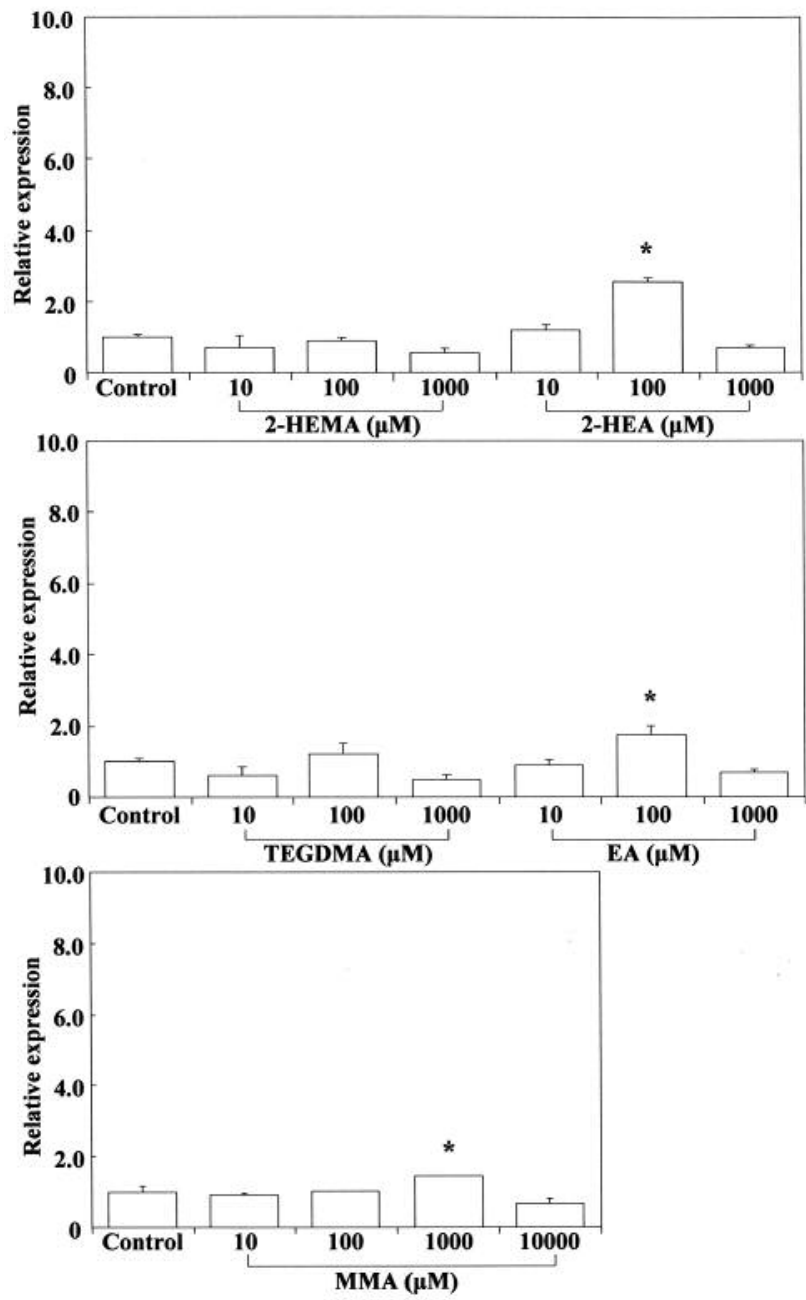

Figure 6. Stimulating effects of 2-hydroxyethyl methacrylate (2-HEMA), 2-hydroxyethyl acrylate (2-HEA), ethyl acrylate (EA), triethylenglycol dimethacrylate (TEGDMA) and methyl methacrylate (MMA) on heme oxygenase 1 (Ho1) mRNA expression in RAW264.7 cells. The cells were incubated for $3.5 \mathrm{~h}$ with each acrylate-related compound at a concentration of 10-1,000 $\mu \mathrm{M}$, and then their total RNAs were prepared. Each cDNA was synthesized, and the expression level of Hol mRNA was determined by real-time polymerase chain reaction and standardized against the expression of $18 \mathrm{~s}$ rRNA. The results are presented as means \pm standard error (SE) of three independent experiments, $S E<15 \%$. $*$ Significantly different at $p<0.01 \mathrm{vs}$. control group.

Stimulation of Hol mRNA expression by cinnamates and (meth)acrylates. The results are shown in Figures 4 and 6. HO1 expression is enhanced not only by free heme, but also by various pro-inflammatory agents such as NO, LPS, cytokines, heavy metals, and other oxidants (56-59). Cinnamaldehyde and methyl cinnamate did not elicit any Hol mRNA expression over a wide concentration range of 0.1-10 mM. In contrast, 
2-hydroxyethyl acrylate and ethyl acrylate at $0.1 \mathrm{mM}$ potently elicited expression of Hol mRNA whereas methyl methacrylate did so poorly at the high concentration of $1 \mathrm{mM}$. Cinnamates with phenyl substituents at the $\beta$-carbons ( $\beta$-phenyl acrylates) and methacrylates with methyl substituents at the $\alpha$-carbons did not elicit $\mathrm{Hol}$ gene expression at non-cytotoxic concentrations. In contrast, acrylates without any substituents at both the $\alpha$-and $\beta$-carbons elicited potent Hol gene expression. Michael addition of methane thiol $\left(\mathrm{CH}_{3} \mathrm{SH}\right)$, a model nucleophile of $\mathrm{GSH}$, was performed previously at the $\mathrm{B} 3 \mathrm{LYP} / 6-31 \mathrm{G}^{*}$ level for 47 Michael reaction acceptors, including $\alpha, \beta$-unsaturated aldehydes, ketones and esters, focusing on the 1,2-olefin addition pathway without and with initial protonation. Michael reaction acceptors such as acrylates may be formed preferentially by direct 1,2 addition across the electron-poor double bond $\mathrm{C}_{\beta}=\mathrm{C}_{\alpha}$ of Michael reaction acceptors (60). Induction of $\mathrm{Ho} 1$ gene expression by acrylates may be attributable to the high electrophilicity of their $\mathrm{C}_{\beta}=\mathrm{C}_{\alpha}$ bond, which lacks substituents at the $\alpha$-and $\beta$-carbons. These findings suggest that induction of $\mathrm{Hol}$ gene expression may be attributable to respective differences in the electrophilicity of $\beta$-arbon $\left(\delta \mathrm{C}_{\beta}\right)$ and steric interactions, as cinnamates with $\beta$-phenyl substituents and methacrylates with $\alpha$-methyl substituents at the $\mathrm{C}_{\beta}=\mathrm{C}_{\alpha}$ bonds did not elicit $\mathrm{Hol}$ mRNA expression in the present study. Interestingly, methyl methacrylate weakly elicited $\mathrm{Hol}$ mRNA expression. Therefore, we also calculated the $\sigma$ values for some (meth)acrylates using the B3LYP/6-31G* level (30), which yielded a $\sigma$ value $(\mathrm{eV})$ rank order of methyl methacrylates $(0.329)>$ TEGDMA $(0.327)$ $>$ ethyl acrylate $(0.323)>2$-hydroxyethyl methacrylates $(0.322)$. Methyl methacrylate had a relatively high $\sigma$ value. This compound may be an excitable molecule, although its $\omega$ value is relatively small (Table II).

Talalay et al. (15) reported that methyl acrylate is a potent inducer of NQORI in Hepa 1c1c7 cells, whereas cinnamaldehyde and methyl cinnamates are weakly effective and methyl methacrylate and cinnamic acid are inactive. Induction of NQORI expression in the human hepatoma cell line HepG2 was measured at both enzyme activity and RNA level after exposure to methyl acrylates and ethyl acrylate (61), the results suggesting that both compounds are potent inducers of HepG2 gene expression. The inductive potency is reliable, and may be related to anti-inflammatory activity via induction of $\mathrm{HOl}$ expression. Expression of the phase II detoxication gene $N Q O R I$ is related to expression the $\mathrm{HOl}$ gene and protein.

A PubMed search of recent articles on nuclear factorerythroid related factor-2 (NRF2), $\mathrm{HO}$ and Ketch-like ECHassociated protein (KEAP1), an oxidative stress sensor, suggested that under normal physiological conditions, NRF2 in the cytoplasm is bound to its repressor, KEAP1. Upon activation, NRF2 is translocated to the nucleus and binds to the antioxidant response element located in the promoter region of some anti-oxidant genes, including that for the cytoprotective protein $\mathrm{HO}$. Since the $\mathrm{HOl}$ gene harbors a binding site for $N R F 2$, mutual stimulatory and regulatory interactions between $N R F 2$ and $\mathrm{HOl}$ have been reported, and in fact the interaction between $N R F 2$ and $\mathrm{HOl}$ has been implicated in the regulation of many physiological antioxidants, including superoxide dismutase, catalase, glutathione S-transferase, peroxidase, NQOR1, and thioredoxin $(62,63)$.

In other contexts, research on $\mathrm{HOl}$ induction by cinnamaldehyde has revealed that the latter up-regulated the cellular protein level of $\mathrm{HOI}$ and promoted translocation of NRF2 to the nucleus in human dental pulp cells. Cinnamaldehyde-mediated NRF2/HO1 activation reduced the level of reactive oxygen species (ROS) and protected human dental pulp cells from $\mathrm{H}_{2} \mathrm{O}_{2}$-induced oxidative stress, which induced apoptosis (64). In contrast, it has been reported that overexpression of $N F K B$ p 65 mRNA induced by high levels of glucose was markedly and dosedependently attenuated by cinnamaldehyde in an in vitro dorsal root ganglion neuron model of diabetic neuropathy, whereas the expression of $N R F 2$ and $\mathrm{HOl}$ was not upregulated (65). NRF2/HO- 1 activation and the signaling mechanisms involved may be dependent on the cell species, inducers employed and reaction time.

In the present study, 2-hydroxyethyl acrylate and ethyl acrylate potently elicited $\mathrm{Hol}$ mRNA expression at low noncytotoxic concentrations, suggesting that these electrophilic compounds may be protective against inflammation, oxidative damage, and cell death. Carbon monoxide, another byproduct of heme degradation by $\mathrm{HO}$, inhibits $\mathrm{NO}$ secretion and reduces inflammation. Up-regulation of $\mathrm{Hol}$ mRNA expression for $\alpha, \beta$-unsaturated carbonyl compounds may be associated with induction of NQORI $(15,16)$. HO1 exerts a strong antioxidant and antiapoptotic effect favoring cancer cell growth (58). However, these active acrylates show marked cytotoxicity and pro-inflammatory activity and are well known to be toxic, allergic and mutagenic. Further studies of these compounds will be necessary to clarify the effects of $\mathrm{HOl}$ expression at the gene and protein level.

Inhibitory effects on P. gingivalis LPS-stimulated expression of Cox2, Nos 2 and Tnfa mRNA. LPS is known to induce high levels of ROS, thus promoting cytotoxicity, apoptosis, and proinflammatory activity. A high level of ROS modulates a number of cell signaling pathways and regulates the expression of multiple genes such as those for COX2 and NOS2 in vitro and in vivo (66). In general, inflammatory activity is accompanied by overexpression of inducible nitric oxide synthase, INOS, leading to production of nitric oxide, which enhances the catalytic activity of $\operatorname{COX} 2$ via formation of the peroxiynitrite anion (22). COX2 is a downstream target of NOS2.

The inhibitory activity of cinnamates against the expression of $P$. gingivalis LPS-stimulated Cox 2 , Nos 2 or Tnfa mRNA is shown in Figure 7. Cinnamaldehyde 


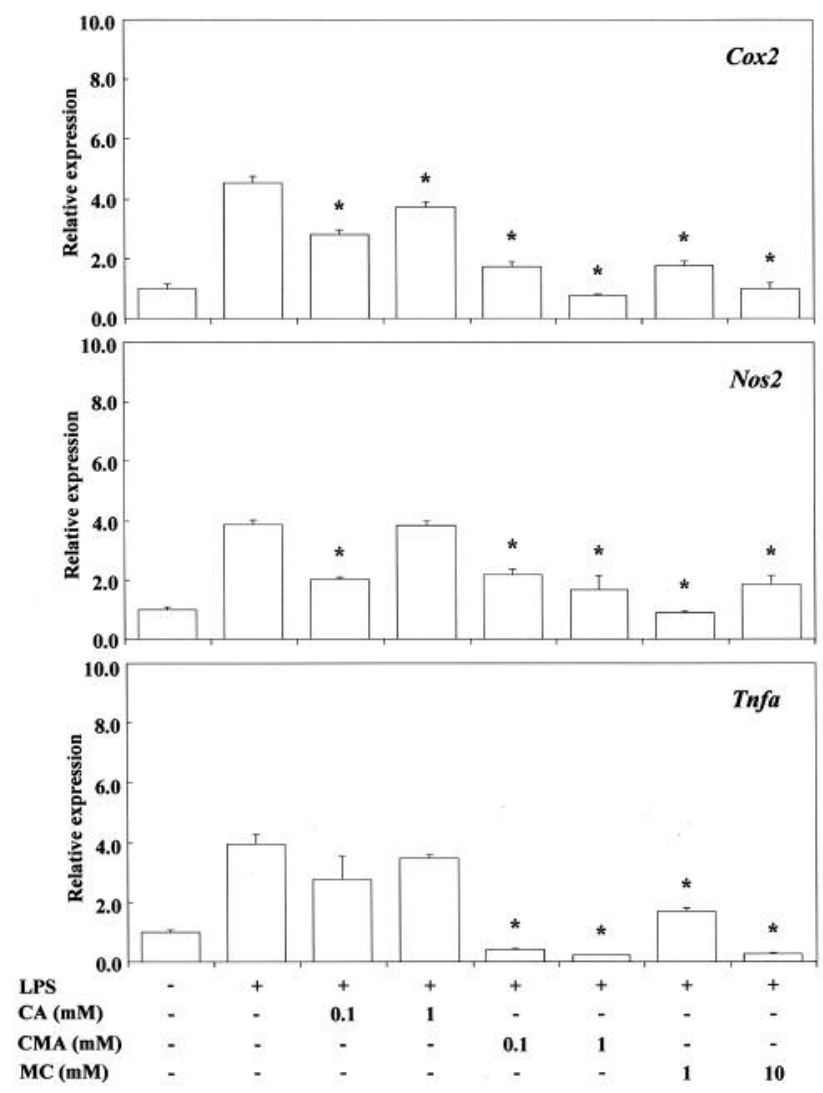

Figure 7. Effects of trans-cinnamic acid (CA), trans-cinnamaldehyde (CMA) and methyl cinnamate (MC) on Porphyromonas gingivalis lipopolysaccharide (LPS)-stimulated cyclo-oxygenase-2 (Cox2), nitric oxide synthase 2 (Nos2) and tumor necrosis factor-alpha (Tnfa) mRNA expression in RAW264.7 cells. The cells were pretreated for 30 min with the indicated doses of compounds, then they were incubated for $3 \mathrm{~h}$ with or without P. gingivalis LPS at $100 \mathrm{ng} / \mathrm{ml}$, and their total RNAs were prepared. Each cDNA was synthesized, and the expression level of each mRNA was determined by real-time polymerase chain reaction and standardized against the expression of $18 s$ rRNA. The results are presented as means \pm standard error (SE) of three independent experiments, $S E<15 \%$. *Significantly different at $p<0.01$ vs. LPS-treated group.

suppressed Cox 2, Nos 2 or Tnfa mRNA expression at a concentration of 0.1-1 mM, and methyl cinnamate did so at concentrations of 1-10 mM. In contrast, cinnamic acid had no effect. This may be due to the fact that free carboxyl groups weaken the efficiency of Michael reaction acceptors. Cinnamaldehyde, but not cinnamic acid, cinnamic alcohol and coumarin, inhibits the production of NO, TNF $\alpha$ and PGE2 by LPS-stimulated RAW264.7 cells (1). Cinnamaldehyde was also reported to inhibit the inflammatory activity of LPS-stimulated macrophages via suppression of mitogen-activated protein kinase (MAPK) phosphorylation and pro-inflammatory gene expression

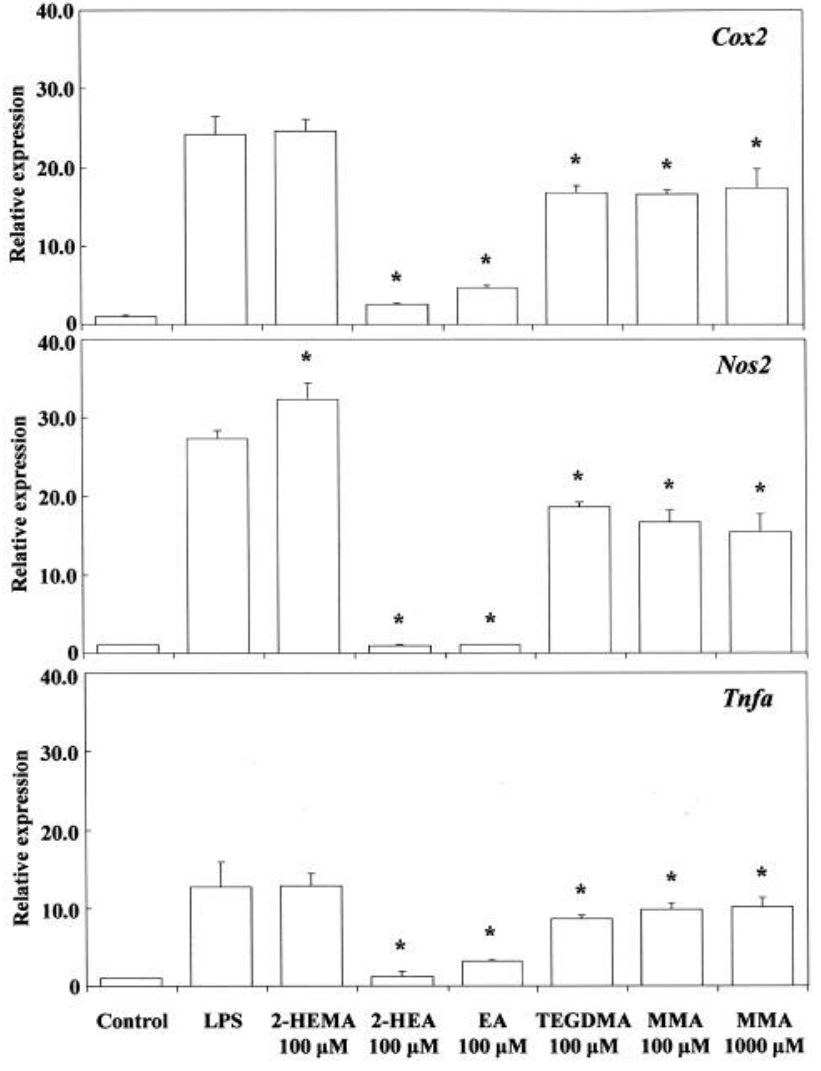

Figure 8. Effects of 2-hydroxyethyl methacrylate (2-HEMA), 2-hydroxyethyl acrylate (2-HEA), ethyl acrylate (EA), triethylenglycol dimethacrylate (TEGDMA) and methyl methacrylate (MMA) on Porphyromonas gingivalis lipopolysaccharide (LPS)-stimulated cyclo-oxygenase-2 (Cox2), nitric oxide synthase 2 (Nos2) and tumor necrosis factor-alpha (Tnfa) mRNA expression in RAW264.7 cells. The cells were pretreated for $30 \mathrm{~min}$ with the indicated doses of compounds, they were then incubated for $3 \mathrm{~h}$ with or without $P$. gingivalis LPS at $100 \mathrm{ng} / \mathrm{ml}$, and their total RNAs were prepared. Each cDNA was synthesized, and the expression level of each mRNA was determined by real-time polymerase chain reaction and standardized against the expression of $18 \mathrm{~s}$ rRNA. The results are presented as means \pm standard error (SE) of three independent experiments, $S E<15 \%$. *Significantly different at $p<0.01$ vs. LPS-treated group.

(67). Furthermore, it has been reported that when RAW264.7 macrophages were treated with cinnamaldehyde together with $E$. coli LPS, significant concentration-dependent inhibition of NO, TNF $\alpha$, and PGE2 production was detected (1). It was also reported that cinnamaldehyde exerts a suppressive effect on tolllike-receptor-4 (TLR4)-mediated signaling and that this effect occurs through inhibition of receptor oligomerization (68). In contrast, cinnamic acid showed only low anti-inflammatory activity in a LPS-inducible inflammatory model in vitro (1), similarly to the findings of the present study. 
Next, we investigated the effects of acrylates and methacrylates on $P$. gingivalis LPS-stimulated expression of Cox2, Nos2 and Tnfa mRNA. The results are shown in Figure 8. Expression of Cox2, Nos2 and Tnfa mRNA was markedly and significantly suppressed by $0.1 \mathrm{mM}$ 2-hydroxyethyl acrylates and ethyl acrylate, particularly the former, but only weakly by TEGDMA and methyl methacrylate, even at a highly cytotoxic concentration of 1 $\mathrm{mM}$, the inhibitory effect being less than 50\%. Cell-surface antigens and cytokines in macrophages have been reported to be up-regulated after exposure to LPS, whereas TEGDMA causes significant down-regulation dependent on exposure time. LPS and TEGDMA act differently on MAPK (69). In the present study, 2-hydroxyethyl methacrylate did not suppress the expression of $\operatorname{Cox} 2$ and Tnfa mRNA, but elicited overexpression of Nos 2 mRNA. The reason is not known. Comparison of the anti-inflammatory activity of cinnamates with that of (meth)acrylates in terms of suppression of Cox2, Nos 2 and Tnfa mRNA expression suggested that cinnamaldehyde and methyl cinnamate preferentially suppressed the expression of Tnfa in comparison with Nos 2 or $\operatorname{Cox} 2$, whereas 2-hydroxyethy acrylate and ethyl acrylate appeared to preferentially suppress Nos 2 gene expression in comparison with Cox 2 or Tnfa (Figures 7 and 8). It is well known that LPS can directly activate macrophages, which trigger the production of inflammation mediators such as NO and TNF $\alpha$ at the protein level. Cinnamaldehyde suppresses LPS-induced production of $\mathrm{NO}$ and the expression of inflammatory protein products such as INOS, COX2 and TNF $\alpha$. Proinflammatory cytokines such as TNF $\alpha$ are small secreted proteins which mediate and regulate immunity and inflammation. Production of TNF $\alpha$ is crucial for the synergistic induction of NO synthesis in LPS-stimulated macrophages in the presence of synapic acid (70). Cinnamates preferentially inhibit TNF $\alpha$ with LPS (71). When RAW264.7 cells are treated with cinnamaldehyde together with LPS for $24 \mathrm{~h}$, the $\mathrm{IC}_{50}$ value required for inhibition of PGE2 production was about $37.7 \mu \mathrm{M}$, whereas that for $\mathrm{TNF} \alpha$ production was about $30 \mu \mathrm{M}$ (1). Cinnamaldehyde inhibited production of TNF $\alpha$ more strongly than that of PGE2 at the protein level. This marked ability of cinnamaldehyde to inhibit the production of TNF $\alpha$ at the protein level was similar to that of cinnamaldehyde at the gene level in the present study. Although cinnamaldehyde, 2-hydroxyethyl acrylate and ethyl acrylate had excellent anti-inflammatory properties, they also had potent pro-inflammatory properties. In contrast, methyl cinnamate had excellent anti-inflammatory properties together with slight cytotoxic and pro-inflammatory properties. Therefore, methyl cinnamate may have potential anti-inflammatory applications against periodontal disease and related systemic conditions. $\alpha, \beta$-Unsaturated carbonyl compounds may exert dual proand anti-inflammatory properties. These compounds may not be ideal for drug design because of their tendency to undergo the Michael addition reaction leading to undesirable sideeffects such as cytotoxicity, skin allergy, mutagenicity and carcinogenicity. Despite such side-effects, these agents may exert a range of beneficial effects similar to those of nonsteroidal anti-inflammatory drugs, including antiinflammatory and anticancer activity (72).

Cinnamaldehyde, a major chemical component of the cinnamon tree, has been shown to induce cellular ROS generation, leading to expression of the COX2 and NOS2 genes, and possibly apoptotic cell death. Cinnamaldehyde has an active Michael acceptor pharmacophore and is generally considered safe, with approval for use in the United States (73). It is noteworthy that some nucleophiles such as water, hydroxy anion $\left(\mathrm{OH}^{-}\right), \mathrm{O}_{2}{ }^{--}$radical, peroxy radical $\left(\mathrm{ROO}^{\circ}\right)$, nitric oxide $\left(\mathrm{NO}^{\circ}\right)$ and GSH may be able to interact with the electrophilic $\beta$-carbon of cinnamates. LPStreated cells generate a large amount of ROS/reactive nitrogen species (RNS) due to oxidative stress. It has been reported that cinnamaldehyde attenuates the release of ROS release from LPS-stimulated J774A.1 macrophages (71). Cinnamates without a phenolic O-H group may also be capable of scavenging more cellular ROS/RNS. Cinnamaldehyde scavenged 1,1-diphenyl-2-picrylhydrazyl (DPPH) free radicals, NO and superoxide radicals (74). Cinnamic acid also scavenged DPPH radicals (data not shown). Cinnamaldehyde and cinnamic acid possess antioxidative and anti-peroxidative properties. However, induction of $\mathrm{Hol}$ gene expression by these electrophilic antioxidative compounds was not observed in the present study using RAW264.7 cells. Cinnamaldehyde also was a prooxidative compound because of its up-regulation of Cox 2 and Nos2. This may be attributed to a great prooxidative activity due to the highly electrophilic aldehyde moiety present in this compound. Cinnamaldehyde might suppress LPS-stimulated Cox2, Nos 2 and Tnfa gene expression through inactivation of the NF-kB pathway, but not through activation of NF2/HO1 in RAW264.7 cells. Further studies will be needed to clarify the signaling mechanisms involved in the anti-inflammatory and pro-inflammatory activities of $\alpha, \beta$-unsaturated carbonyl compounds.

In conclusion, $\alpha, \beta$-unsaturated carbonyl compounds such as cinnamates (CMA, MC) and acrylates (2-HEA, EA) but not methacrylates (2-HEMA, MMA, TEGDMA) potently suppressed $P$. gingivalis LPS-stimulated Cox2, Nos 2 and Tnfa mRNA expression. Treatment with two acrylates up-regulated Hol mRNA expression. The Michael addition in biological systems is a likely molecular mechanism for the toxicity and pro-/antiinflammatory property of such compounds. MC had little cytotoxicity and anti-inflammatory activity. 


\section{Acknowledgements}

This work was supported by JSPS KAKENHI Grant Number JP15K11266 from the Ministry of Education, Science, and Culture of Japan.

\section{References}

1 Liao JC, Deng JS, Chiu CS, Hou WC, Huang SS, Shie PH and Huang GJ: Anti-inflammatory activities of Cinnamomum cassia constituents in vitro and in vivo. Evid Based Complement Alternat Med 2012: 429320, 2012.

2 Lee HS, Kim BS and Kim MK: Suppression effect of Cinnamomum cassia bark-derived component on nitric oxide synthase. J Agric Food Chem 50: 7700-7703, 2002.

3 Hancı D, Altun H, Çetinkaya EA, Muluk NB, Cengiz BP and Cingi C: Cinnamaldehyde is an effective anti-inflammatory agent for treatment of allergic rhinitis in a rat model. Int $\mathrm{J}$ Pediatr OtorhinolaryngoI 84: 81-87, 2016.

4 Roth-Walter F, Moskovskich A, Gomez-Casado C, Diaz-Perales A, Oida K, Singer J, Kinaciyan T, Fuchs HC and Jensen-Jarolim E: Immune-suppressive effect of cinnamaldehyde due to inhibition of proliferation and induction of apoptosis in immune cells: implications in cancer. PLoS One 9: e108402, 2014.

5 de Cássia da Silveira E Sá R, Andrade LN, Dos Reis Barreto de Oliveira $\mathrm{R}$ and de Sousa DP: A review on anti-inflammatory activity of phenylpropanoids found in essential oils. Molecules 19: 1459-1480, 2014.

6 Gunawardena D, Karunaweera N, Lee S, van Der Kooy F, Harman DG, Raju R, Bennett L, Gyengesi E, Sucher NJ and Münch G: Anti-inflammatory activity of cinnamon $(C$. zeylanicum and C. cassia) extracts - identification of Ecinnamaldehyde and o-methoxy cinnamaldehyde as the most potent bioactive compounds. Food Funct 6: 910-919, 2015.

7 Niero EL and Machado-Santelli GM: Cinnamic acid induces apoptotic cell death and cytoskeleton disruption in human melanoma cells. J Exp Clin Cancer Res 32: 31, 2013.

8 Scheinman PL: Allergic contact dermatitis to fragrance: A review. Am J Contact Dermat 7: 65-76, 1996.

9 Aptula AO and Roberts DW: Mechanistic applicability domains for nonanimal-based prediction of toxicological end points: General principles and application to reactive toxicity. Chem Res Toxicol 19: 1097-1105, 2006.

10 Chan K and O'Brien PJ: Structure-activity relationships for hepatocyte toxicity and electrophilic reactivity of alpha,betaunsaturated esters, acrylates and methacrylates. J Appl Toxicol 28: 1004-1015, 2008.

11 Gosavi SS, Gosavi SY and Alla RK: Local and systemic effects of unpolymerised monomers. Dent Res J 7: 82-87, 2010.

12 LoPachin RM and Gavin T: Molecular mechanisms of aldehyde toxicity: a chemical perspective. Chem Res Toxicol 27: 10811091, 2014.

13 Jackson PA, Widen JC, Harki DA and Brummond KM: Covalent Modifiers: A chemical perspective on the reactivity of $\alpha, \beta$ unsaturated carbonyls with thiols via hetero-Michael addition reactions. J Med Chem 60: 839-885, 2017.

14 Rossi A, Kapahi P, Natoli G, Takahashi T, Chen Y, Karin M and Santoro MG: Anti-inflammatory cyclopentenone prostaglandins are direct inhibitors of IkappaB kinase. Nature 403: 103-108, 2000 .
15 Talalay P, De Long MJ and Prochaska HJ: Identification of a common chemical signal regulating the induction of enzymes that protect against chemical carcinogenesis. Proc Natl Acad Sci USA 85: 8261-8265, 1988.

16 Dinkova-Kostova AT, Massiah MA, Bozak RE, Hicks RJ and Talalay P: Potency of Michael reaction acceptors as inducers of enzymes that protect against carcinogenesis depends on their reactivity with sulfhydryl groups. Proc Natl Acad Sci USA 98: 3404-3409, 2001.

17 Dinkova-Kostova AT, Liby KT, Stephenson KK, Holtzclaw WD, Gao X, Suh N, Williams C, Risingsong R, Honda T, Gribble GW, Sporn MB and Talalay P: Extremely potent triterpenoid inducers of the phase 2 response: Correlations of protection against oxidant and inflammatory stress. Proc Natl Acad Sci USA 102: 4584-4589, 2005.

18 Liu H, Dinkova-Kostova AT and Talalay P: Coordinate regulation of enzyme markers for inflammation and for protection against oxidants and electrophiles. Proc Natl Acad Sci USA 105: 1592615931, 2008.

19 Kensler TW: Chemoprevention by inducers of carcinogen detoxication enzymes. Environ Health Perspect 105: 965-970, 1997.

20 De Long MJ, Prochaska HJ and Talalay P: Induction of $\mathrm{NAD}(\mathrm{P}) \mathrm{H}$ :quinone reductase in murine hepatoma cells by phenolic antioxidants, azo dyes, and other chemoprotectors: A model system for the study of anticarcinogens. Proc Natl Acad Sci USA 83: 787-791, 1986.

21 Perez JL, Jayaprakasha GK, Cadena A, Martinez E, Ahmad H and Patil BS: In vivo induction of phase II detoxifying enzymes, glutathione transferase and quinone reductase by citrus triterpenoids. BMC Complement Altern Med 10: 51, 2010.

22 Salvemini D, Kim SF and Mollace V: Reciprocal regulation of the nitric oxide and cyclooxygenase pathway in pathophysiology: relevance and clinical implications. Am J Physiol Regul Integr Comp Physiol 304: R473-487, 2013.

23 Agarwal A and Bolisetty S: Adaptive responses to tissue injury: Role of heme oxygenase-1. Trans Am Clin Climatol Assoc 124: 111-122, 2013.

24 Yamada N, Yamaya M, Okinaga S, Nakayama K, Sekizawa K, Shibahara S and Sasaki H: Microsatellite polymorphism in the heme oxygenase-1 gene promoter is associated with susceptibility to emphysema. Am J Hum Genet 66: 187-195, 2000.

25 Gabunia K, Ellison SP, Singh H, Datta P, Kelemen SE, Rizzo V and Autieri MV: Interleukin-19 (IL-19) induces heme oxygenase-1 (HO1) expression and decreases reactive oxygen species in human vascular smooth muscle cells. J Biol Chem 287: 2477-2484, 2012.

26 Seymour GJ, Ford PJ, Cullinan MP, Leishman S and Yamazaki $\mathrm{K}$ : Relationship between periodontal infections and systemic disease. Clin Microbiol Infect 13: 3-10, 2007.

27 Nicholas C, Batra S, Vargo MA, Voss OH, Gavrilin MA, Wewers MD, Guttridge DC, Grotewold E and Doseff AI: Apigenin blocks lipopolysaccharide-induced lethality in vivo and proinflammatory cytokines expression by inactivating NFkappaB through the suppression of $\mathrm{p} 65$ phosphorylation. $\mathrm{J}$ Immunol 179: 7121-7127, 2007.

28 Ryu EY, Park SY, Kim SG, Park DJ, Kang JS, Kim YH, Seetharaman R, Choi YW and Lee SJ: Anti-inflammatory effect of heme oxygenase-1 toward Porphyromonas gingivalis lipopolysaccharide in macrophages exposed to gomisins A, G, and J. J Med Food 14: 1519-1526, 2011. 
29 Motterlini R and Foresti R: Heme oxygenase- 1 as a target for drug discovery. Antioxid Redox Signal 20: 1810-1826, 2014.

30 Murakami Y, Kawata A and Fujisawa S: Expression of cyclooxygenase-2, nitric oxide synthase 2 and heme oxygenase1 mRNA induced by bis-eugenol in RAW264.7 cells and their antioxidant activity determined using the induction period method. In Vivo 31: 819-831, 2017.

31 Fujisawa S, Murakami Y: Eugenol and its role in chronic diseases. Adv Exp Med Biol 929: 45-66, 2016.

32 Ishiyama M, Miyazono Y, Sasamoto K, Ohkura Y and Ueno K: A highly water-soluble disulfonated tetrazolium salt as a chromogenic indicator for NADH as well as cell viability. Talanta 44: 1299-1305, 1997.

33 Murakami Y, Kawata A, Seki Y, Koh T, Yuhara K, Maruyama T, Machino M, Ito S, Kadoma $Y$ and Fujisawa S: Comparative inhibitory effects of magnolol, honokiol, eugenol and bis-eugenol on cyclooxygenase-2 expression and nuclear factor-kappa B activation in RAW264.7 macrophage-like cells stimulated with fimbriae of Porphyromonas gingivalis. In Vivo 26: 941-950, 2012.

34 Frederick $\mathrm{CB}$ and Reynolds $\mathrm{CH}$ : Modeling the reactivity of acrylic acid and acrylate anion with biological nucleophiles. Toxicol Lett 47: 241-247, 1989.

35 Atsumi T, Fujisawa S and Tonosaki K: (Meth)acrylate monomerinduced cytotoxicity and intracellular $\mathrm{Ca}(2+)$ mobilization in human salivary gland carcinoma cells and human gingival fibroblast cells related to monomer hydrophobicity. Biomaterials 27: 5794-5800, 2006

36 Pinton P, Giorgi C, Siviero R, Zecchini E and Rizzuto R: Calcium and apoptosis: ER-mitochondria $\mathrm{Ca}^{2+}$ transfer in the control of apoptosis. Oncogene 27: 6407-6418, 2008.

37 Fujisawa S and Kadoma Y: Prediction of the reduced glutathione $(\mathrm{GSH})$ reactivity of dental methacrylate monomers using NMR spectra - Relationship between toxicity and GSH reactivity. Dent Mater J 28: 722-729, 2009.

38 Fujisawa $\mathrm{S}$ and Kadoma Y: Mechanisms of action of (meth)acrylates in hemolytic activity, in vivo toxicity and dipalmitoylphosphatidylcholine (DPPC) liposomes determined using NMR spectroscopy. Int J Mol Sci 13: 758-773, 2012.

39 Swales NJ and Caldwell J: Studies on trans-cinnamaldehyde II: Mechanisms of cytotoxicity in rat isolated hepatocytes. Toxicol In Vitro 10: 37-42, 1996.

40 Guimarães MR, de Aquino SG, Coimbra LS, Spolidorio LC, Kirkwood KL and Rossa C Jr.: Curcumin modulates the immune response associated with LPS-induced periodontal disease in rats. Innate Immun 18: 155-163, 2012.

41 Funk CD: Prostaglandins and leukotrienes: advances in eicosanoid biology. Science 294: 1871-1875, 2001.

42 Ricciotti E and FitzGerald GA: Prostaglandins and inflammation. Arterioscler Thromb Vasc Biol 31: 986-1000, 2011.

43 Isaac-Renton M, Li MK and Parsons LM: Cinnamon spice and everything not nice: many features of intraoral allergy to cinnamic aldehyde. Dermatitis 26: 116-121, 2015.

44 Janzowski C, Glaab V, Mueller C, Straesser U, Kamp HG and Eisenbrand G: Alpha, beta-unsaturated carbonyl compounds: induction of oxidative DNA damage in mammalian cells. Mutagenesis 18: 465-470, 2003.

45 Pérez-Garrido A, Helguera AM, Rodríguez FG and Cordeiro $\mathrm{MN}$ : QSAR models to predict mutagenicity of acrylates, methacrylates and alpha,beta-unsaturated carbonyl compounds. Dent Mater 26: 397-415, 2010.
46 Mohammad MK, Avila D, Zhang J, Barve S, Arteel G, McClain $\mathrm{C}$ and Joshi-Barve S: Acrolein cytotoxicity in hepatocytes involves endoplasmic reticulum stress, mitochondrial dysfunction and oxidative stress. Toxicol Appl Pharmacol 265: 73-82, 2012.

47 Ohta T, Watanabe K, Moriya M, Shirasu Y and Kada T: Antimutagenic effects of cinnamaldehyde on chemical mutagenesis in Escherichia coli. Mutat Res 107: 219-227, 1983.

48 Tracey KJ and Cerami A: Tumor necrosis factor: A pleiotropic cytokine and therapeutic target. Annu Rev Med 45: 491-503, 1994.

49 Lee DH, Kim NR, Lim BS, Lee YK and Yang HC: Effects of TEGDMA and HEMA on the expression of COX2 and iNOS in cultured murine macrophage cells. Dent Mater 25: 240-246, 2009.

50 Ishihara $\mathrm{M}$ and Fujisawa S: A structure-activity relationship study on the mechanisms of methacrylate-induced toxicity using NMR chemical shift of beta-carbon, RP-HPLC $\log$ P and semiempirical molecular descriptor. Dent Mater J 28: 113-120, 2009.

51 Fujisawa $\mathrm{S}$ and Kadoma Y: Anti-and pro-oxidant effects of oxidized quercetin, curcumin or curcumin-related compounds with thiols or ascorbate as measured by the induction period method. In Vivo 20: 39-44, 2006.

52 Ishihara $\mathrm{M}$ and Fujisawa S: Quantum-chemical descriptors for estimating hemolytic activity of aliphatic and aromatic methacrylates. Chemosphere 70: 1898-1902, 2008.

53 Enoch SJ, Madden JC and Cronin MT: Identification of mechanisms of toxic action for skin sensitisation using a SMARTS pattern based approach. SAR QSAR Environ Res 19: 555-578, 2008

54 LoPachin RM, Gavin T, Geohagen BC, Zhang L, Casper D, Lekhraj R and Barber DS: $\beta$-Dicarbonyl enolates: A new class of neuroprotectants. J Neurochem 116: 132-143, 2011.

55 LoPachin RM, Barber DS and Gavin T: Molecular mechanisms of the conjugated alpha,beta-unsaturated carbonyl derivatives: relevance to neurotoxicity and neurodegenerative diseases. Toxicol Sci 104: 235-249, 2008.

56 Terry CM, Clikeman JA, Hoidal JR and Callahan KS: Effect of tumor necrosis factor-alpha and interleukin-1 alpha on heme oxygenase-1 expression in human endothelial cells. Am J Physiol 274: H883-891, 1998.

57 Chung SW, Liu X, Macias AA, Baron RM and Perrella MA: Heme oxygenase-1-derived carbon monoxide enhances the host defense response to microbial sepsis in mice. J Clin Invest 118 : 239-247, 2008

58 Ryter SW, Alam J and Choi AM: Heme oxygenase-1/carbon monoxide: From basic science to therapeutic applications. Physiol Rev 86: 583-650, 2006.

59 Srisook K and Cha YN: Super-induction of HO1 in macrophages stimulated with lipopolysaccharide by prior depletion of glutathione decreases iNOS expression and NO production. Nitric Oxide 12: 70-79, 2005.

60 Mulliner D, Wondrousch D and Schüürmann G: Predicting Michael-acceptor reactivity and toxicity through quantum chemical transition-state calculations. Org Biomol Chem 9: 8400-8012, 2011.

61 Winner EJ, Prough RA and Brennan MD: Human $\mathrm{NAD}(\mathrm{P}) \mathrm{H}$ :quinone oxidoreductase induction in human hepatoma cells after exposure to industrial acrylates, phenolics, and metals. Drug Metab Dispos 25: 175-181, 1997. 
62 Itoh K, Tong KI and Yamamoto M: Molecular mechanism activating Nrf2-Keap1 pathway in regulation of adaptive response to electrophiles. Free Radic Biol Med 36: 1208-1213, 2004.

63 Ndisang JF: Synergistic interaction between heme oxygenase (HO) and nuclear-factor E2-related factor-2 (NRF2) against oxidative stress in cardiovascular related diseases. Curr Pharm Des 23: 1465-1470, 2017.

64 Kim NY, Ahn SG and Kim SA: Cinnamaldehyde protects human dental pulp cells against oxidative stress through the NRF2/HO1-dependent antioxidant response. Eur J Pharmacol 815: 73-79, 2017.

65 Yang D, Liang XC, Shi Y, Sun Q, Liu D, Liu W and Zhang H: Anti-oxidative and anti-inflammatory effects of cinnamaldehyde on protecting high glucose-induced damage in cultured dorsal root ganglion neurons of rats. Chin J Integr Med 22: 19-27, 2016.

66 Reuter S, Gupta SC, Chaturvedi MM and Aggarwal BB: Oxidative stress, inflammation, and cancer: How are they linked? Free Radic Biol Med 49: 1603-1616, 2010.

$67 \mathrm{Kim}$ ME, Na JY and Lee JS: Anti-inflammatory effects of transcinnamaldehyde on lipopolysaccharide-stimulated macrophage activation via MAPKs pathway regulation. Immunopharmacol Immunotoxicol 2018 Jan 22: 1-6, 2018.

68 Youn HS, Lee JK, Choi YJ, Saitoh SI, Miyake K, Hwang DH and Lee JY: Cinnamaldehyde suppresses toll-like receptor 4 activation mediated through the inhibition of receptor oligomerization. Biochem Pharmacol 75: 494-502, 2008.

69 Schmalz G, Krifka S and Schweikl H: Toll-like receptors, LPS, and dental monomers. Adv Dent Res 23: 302-306, 2011.
70 Yun KJ, Koh DJ, Kim SH, Park SJ, Ryu JH, Kim DG, Lee JY and Lee KT: Anti-inflammatory effects of sinapic acid through the suppression of inducible nitric oxide synthase, cyclooxygase2 , and proinflammatory cytokines expressions via nuclear factorkappaB inactivation. J Agric Food Chem 56: 10265-10272, 2008.

71 Chao LK, Hua KF, Hsu HY, Cheng SS, Lin IF, Chen CJ, Chen ST and Chang ST: Cinnamaldehyde inhibits pro-inflammatory cytokines secretion from monocytes/macrophages through suppression of intracellular signaling. Food Chem Toxicol 46: 220-231, 2008.

72 Arshad L, Jantan I, Bukhari SN and Haque MA: Immunosuppressive Effects of Natural $\alpha, \beta$-unsaturated carbonylbased compounds, and their analogs and derivatives, on immune cells: A review. Front Pharmacol 8: 22, 2017.

73 Cabello CM, Bair WB 3rd, Lamore SD, Ley S, Bause AS, Azimian S and Wondrak GT: The cinnamon-derived Michael acceptor cinnamic aldehyde impairs melanoma cell proliferation, invasiveness, and tumor growth. Free Radic Biol Med 46: 220231, 2009.

74 Subash-Babu P, Alshatwi AA and Ignacimuthu S: Beneficial antioxidative and antiperoxidative effect of cinnamaldehyde protect streptozotocin-induced pancreatic $\beta$-cell damage in Wistar rats. Biomol Ther 22: 47-54, 2014.

Received June 23, 2018

Revised July 17, 2018

Accepted July 19, 2018 